\title{
Correction to: Plethodontid salamanders show variable disease dynamics in response to Batrachochytrium salamandrivorans chytridiomycosis
}

\author{
Graziella V. DiRenzo (D) Ana V. Longo - Carly R. Muletz-Wolz • \\ Allan P. Pessier · Jessica A. Goodheart · Karen R. Lips
}

Published online: 4 June 2021

(C) Springer Nature Switzerland AG 2021

\section{Correction to: Biol Invasions}

https://doi.org/10.1007/s10530-02102536-1

Unfortunately, the original publication of the article has been published with an error in the reference that reads as "Lacey act 1990" should read as Lacey act 1900.

The original article has been corrected.

Publisher's Note Springer Nature remains neutral with regard to jurisdictional claims in published maps and institutional affiliations.
The original article can be found online at https:// doi.org/10.1007/s10530-021-02536-1.

\author{
G. V. DiRenzo $(\bowtie)$ · C. R. Muletz-Wolz · K. R. Lips \\ Department of Biology, University of Maryland, \\ College Park, MD 20744, USA \\ e-mail: gdirenzo@umass.edu \\ C. R. Muletz-Wolz \\ e-mail:muletzc@si.edu \\ K. R. Lips \\ e-mail: klips@umd.edu \\ G. V. DiRenzo \\ Current Address: U. S. Geological Survey, Massachusetts \\ Cooperative Fish and Wildlife Research Unit, University \\ of Massachusetts, Amherst, MA 01003, USA
}
A. V. Longo
Department of Biology, University of Florida,
Gainesville, FL 32611, USA
e-mail: ana.longo@ufl.edu

C. R. Muletz-Wolz

Center for Conservation Genomics, Smithsonian

Conservation Biology Institute, National Zoological Park, Washington, DC 20008, USA
A. P. Pessier
Department of Veterinary Microbiology and Pathology, College of Veterinary Medicine, Washington State University, Pullman, WA 99164, USA
e-mail: apessier@wsu.edu
A. P. Pessier
Institute for Conservation Research, San Diego Zoo
Global, San Diego, CA 92112, USA
J. A. Goodheart
Scripps Institution of Oceanography, University of California, San Diego, La Jolla, CA 92037, USA e-mail: jgoodheart@ucsd.edu

